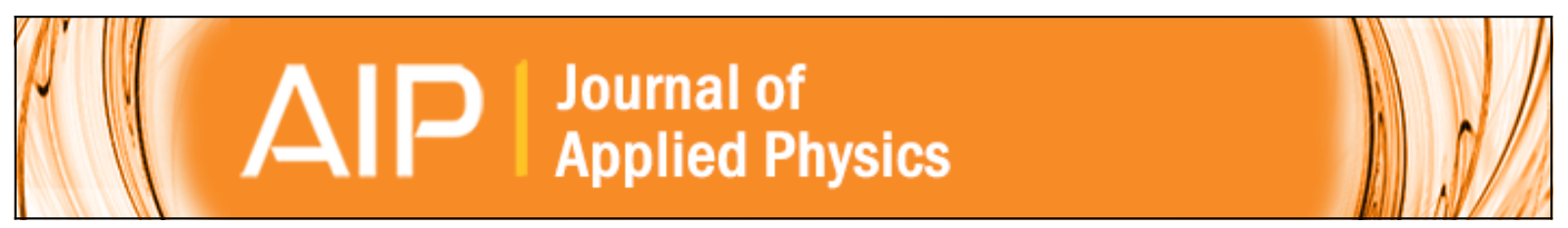

\title{
Electrical and structural properties of In-implanted Si1-xGex alloys
}

R. Feng, F. Kremer, D. J. Sprouster, S. Mirzaei, S. Decoster, C. J. Glover, S. A. Medling, J. L. Hansen, A. Nylandsted-Larsen, S. P. Russo, and M. C. Ridgway

Citation: Journal of Applied Physics 119, 025709 (2016); doi: 10.1063/1.4940046

View online: http://dx.doi.org/10.1063/1.4940046

View Table of Contents: http://scitation.aip.org/content/aip/journal/jap/119/2?ver=pdfcov

Published by the AIP Publishing

\section{Articles you may be interested in}

Porosity as a function of stoichiometry and implantation temperature in Ge/Si1-xGex alloys

J. Appl. Phys. 119, 094303 (2016); 10.1063/1.4942995

Structural and electrical properties of In-implanted Ge

J. Appl. Phys. 118, 165701 (2015); 10.1063/1.4934200

Doping of $\mathrm{Ge}-\mathrm{Si}$ x Ge 1 - x core-shell nanowires using low energy ion implantation

Appl. Phys. Lett. 93, 203108 (2008); 10.1063/1.3013335

Strain relaxation of pseudomorphic Si $1-x \mathrm{Gex} / \mathrm{Si}$ ( 100 ) heterostructures after $\mathrm{Si}+$ ion implantation J. Appl. Phys. 96, 1745 (2004); 10.1063/1.1765851

Structural and electrical properties of $\mathrm{p}+\mathrm{n}$ junctions in Si by low energy $\mathrm{Ga}+$ implantation J. Appl. Phys. 82, 4990 (1997); 10.1063/1.366367

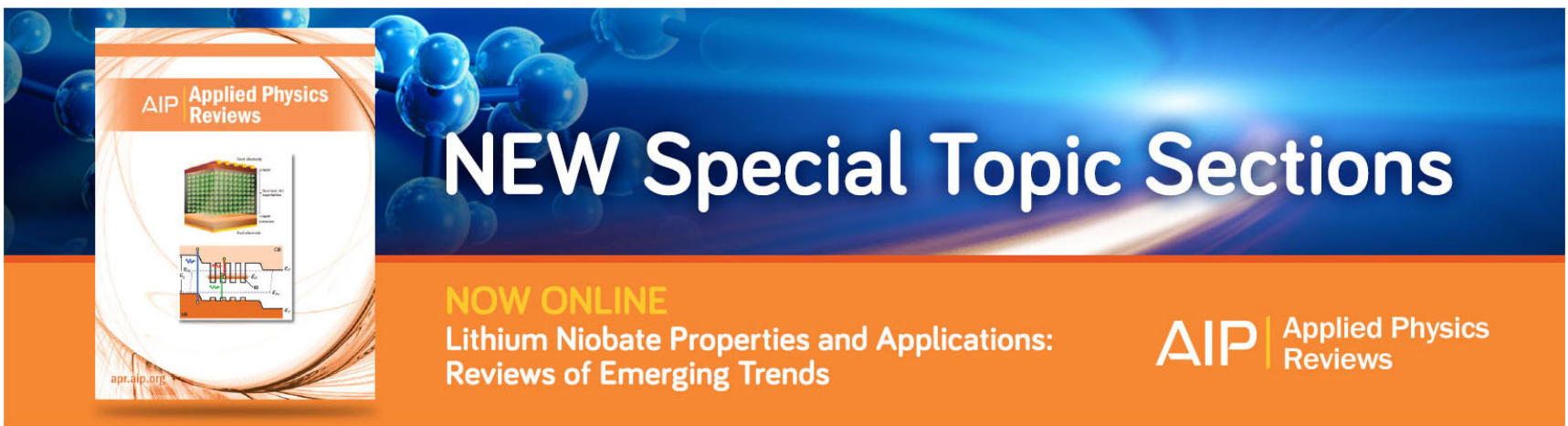




\title{
Electrical and structural properties of In-implanted $\mathrm{Si}_{1-\mathrm{x}} \mathbf{G e}_{\mathbf{x}}$ alloys
}

\author{
R. Feng, ${ }^{1, a)}$ F. Kremer, ${ }^{1}$ D. J. Sprouster, ${ }^{2}$ S. Mirzaei, ${ }^{1}$ S. Decoster, ${ }^{3}$ C. J. Glover, ${ }^{4}$ \\ S. A. Medling, ${ }^{1}$ J. L. Hansen, ${ }^{5}$ A. Nylandsted-Larsen, ${ }^{5}$ S. P. Russo, ${ }^{6}$ and M. C. Ridgway ${ }^{1}$ \\ ${ }^{1}$ Department of Electronic Materials Engineering, Research School of Physics and Engineering, \\ Australian National University, Canberra, ACT 0200, Australia \\ ${ }^{2}$ Nuclear Science and Technology Department, Brookhaven National Laboratory, Upton, New York 11973, \\ USA \\ ${ }^{3}$ KU Leuven, Instituut voor Kern-en Stralingsfysica, 3001 Leuven, Belgium \\ ${ }^{4}$ Australian Synchrotron, 800 Blackburn Road, Clayton, Victoria 3168, Australia \\ ${ }^{5}$ Department of Physics and Astronomy, Aarhus University, DK-8000 Aarhus C, Denmark \\ ${ }^{6}$ Department of Applied Physics, School of Applied Sciences, RMIT University, Melbourne 3001, Australia
}

(Received 19 November 2015; accepted 4 January 2016; published online 14 January 2016)

\begin{abstract}
We report on the effects of dopant concentration and substrate stoichiometry on the electrical and structural properties of In-implanted $\mathrm{Si}_{1-\mathrm{x}} \mathrm{Ge}_{\mathrm{x}}$ alloys. Correlating the fraction of electrically active In atoms from Hall Effect measurements with the In atomic environment determined by X-ray absorption spectroscopy, we observed the transition from electrically active, substitutional In at low In concentration to electrically inactive metallic In at high In concentration. The In solid-solubility limit has been quantified and was dependent on the $\mathrm{Si}_{1-\mathrm{x}} \mathrm{Ge}_{\mathrm{x}}$ alloy stoichiometry; the solid-solubility limit increased as the Ge fraction increased. This result was consistent with density functional theory calculations of two In atoms in a $\mathrm{Si}_{1-\mathrm{x}} \mathrm{Ge}_{\mathrm{x}}$ supercell that demonstrated that $\mathrm{In}-\mathrm{In}$ pairing was energetically favorable for $\mathrm{x} \lesssim 0.7$ and energetically unfavorable for $\mathrm{x} \gtrsim 0.7$. Transmission electron microscopy imaging further complemented the results described earlier with the In concentration and $\mathrm{Si}_{1-\mathrm{x}} \mathrm{Ge}_{\mathrm{x}}$ alloy stoichiometry dependencies readily visible. We have demonstrated that low resistivity values can be achieved with In implantation in $\mathrm{Si}_{1-\mathrm{x}} \mathrm{Ge}_{\mathrm{x}}$ alloys, and this combination of dopant and substrate represents an effective doping protocol. (C) 2016 AIP Publishing LLC.
\end{abstract}

[http://dx.doi.org/10.1063/1.4940046]

\section{INTRODUCTION}

In is a promising $p$-type dopant in both $\mathrm{Si}^{1}$ and $\mathrm{Ge},{ }^{2}$ with substrate-specific advantages and disadvantages toward the application to complementary metal-oxide semiconductor (CMOS) devices. In Si substrates, the low diffusion coefficient of In enables the formation of a super-steep retrograde channel profile (SSRCP) to boost device scaling; ${ }^{1,3,4}$ yet, In has a low solid-solubility limit $(\sim 0.0036 \text { at. } \%)^{5}$ and a deep acceptor level $\left(0.150 \mathrm{eV}\right.$ above the valence band). ${ }^{6}$ In Ge substrates, device electrical performance can be significantly advanced, ${ }^{7}$ with superior carrier mobility, ${ }^{8}$ a higher In solidsolubility limit (>0.02 at. \%), ${ }^{9}$ and a shallower In acceptor level $(0.0112 \mathrm{eV}$ above the valence band $) .{ }^{10}$ Relative to $\mathrm{Si}$, the narrow bandgap of $\mathrm{Ge}$ can, however, yield higher off-state leakage due to band-to-band tunneling (BTBT). ${ }^{11}$

$\mathrm{Si}_{1-\mathrm{x}} \mathrm{Ge}_{\mathrm{x}}$ alloys have the potential to combine the positive aspects of $\mathrm{Si}$ and $\mathrm{Ge}$ substrates to produce a reasonably steep In profile with high electrical activation and, furthermore, relieve the BTBT problem in Ge. While the carrier mobility in $\mathrm{Si}_{1-\mathrm{x}} \mathrm{Ge}_{\mathrm{x}}$ decreases rapidly as the $\mathrm{Si}$ fraction increases, strain engineering in $\mathrm{Si}_{1-\mathrm{x}} \mathrm{Ge}_{\mathrm{x}}$ is regularly utilized to maintain a high carrier mobility. ${ }^{11,12}$ To optimize the trade-off between In concentration and Ge fraction in In-doped $\mathrm{Si}_{1-\mathrm{x}} \mathrm{Ge}_{\mathrm{x}}$, a systematic study of the electrical activation/deactivation kinetics is thus necessary and forms the basis of this report.

\footnotetext{
${ }^{\text {a)} E l e c t r o n i c ~ m a i l: ~ r u i x i n g . f e n g @ a n u . e d u . a u ~}$
}

For In-doped Si and Ge, earlier work has shown that In atoms were electrically active and located on substitutional lattice sites when the In concentration was below the solidsolubility limits. ${ }^{2,4}$ The formation of electrically inactive In metal precipitates ${ }^{1,5,9}$ and In- $\mathrm{V}$ pairs ${ }^{9,13,14}$ (where $\mathrm{V}$ denotes a vacancy) was observed when these thresholds were exceeded. While the electrical and structural properties of In-doped $\mathrm{Si}$ and $\mathrm{Ge}$ have been studied, those of In-doped $\mathrm{Si}_{1-\mathrm{x}} \mathrm{Ge}_{\mathrm{x}}$ have yet to be reported. Hence, in this report we used Hall Effect measurements to determine the electrical properties of In-doped $\mathrm{Si}_{1-\mathrm{x}} \mathrm{Ge}_{\mathrm{x}}$ which were then correlated with the structural properties determined with X-ray absorption spectroscopy (XAS) and transmission electron microcopy (TEM). The dependencies on both In concentration (from 0.02 to 1.2 at. $\%$ ) and $\mathrm{Si}_{1-\mathrm{x}} \mathrm{Ge}_{\mathrm{x}}$ stoichiometry $(\mathrm{x}=0$, $0.65,0.9$ and 1) were investigated, aiming to examine these effects at device-appropriate levels. We also used density functional theory (DFT) to perform a theoretical study of InIn pairing as a function of $\mathrm{Si}_{1-\mathrm{x}} \mathrm{Ge}_{\mathrm{x}}$ stoichiometry and then correlated theoretical and experimental results.

\section{EXPERIMENTAL}

Thin films of thickness $\sim 2.5 \mu \mathrm{m}$ and composition $\mathrm{Si}$, $\mathrm{Si}_{0.35} \mathrm{Ge}_{0.65}, \mathrm{Si}_{0.1} \mathrm{Ge}_{0.9}$, and $\mathrm{Ge}$ were examined. The Si layer was from a commercial SOI (100) wafer, and the $\mathrm{Si}_{0.35} \mathrm{Ge}_{0.65}$ and $\mathrm{Si}_{0.1} \mathrm{Ge}_{0.9}$ layers were deposited by molecular beam epitaxy on (100) Si substrates, while the Ge layer was deposited by ultra-high-vacuum chemical vapor deposition a (100) $\mathrm{Si}$ 
substrate. We used thin layers to enable the subsequent removal of the Si substrate for superior synchrotron-based measurements. ${ }^{9}$ The influence of misfit dislocations near the thin layer/Si substrate interface was minimized by confining the implanted In depth distributions to at least $0.5 \mu \mathrm{m}$ above the interface. Implantations were performed at $250^{\circ} \mathrm{C}$ to avoid amorphization, and the surface normal was offset $7^{\circ}$ from the incident ion direction to avoid channeling. In implantation energies ranged from 700 to $3400 \mathrm{keV}$ with fluences varying from $1.31 \times 10^{14}$ to $5.44 \times 10^{16}$ ions $/ \mathrm{cm}^{2}$ to produce uniform depth distributions over $0.5-1.5 \mu \mathrm{m}$, as calculated with TRIM2008. ${ }^{15}$ More details of the implantation process are given in a
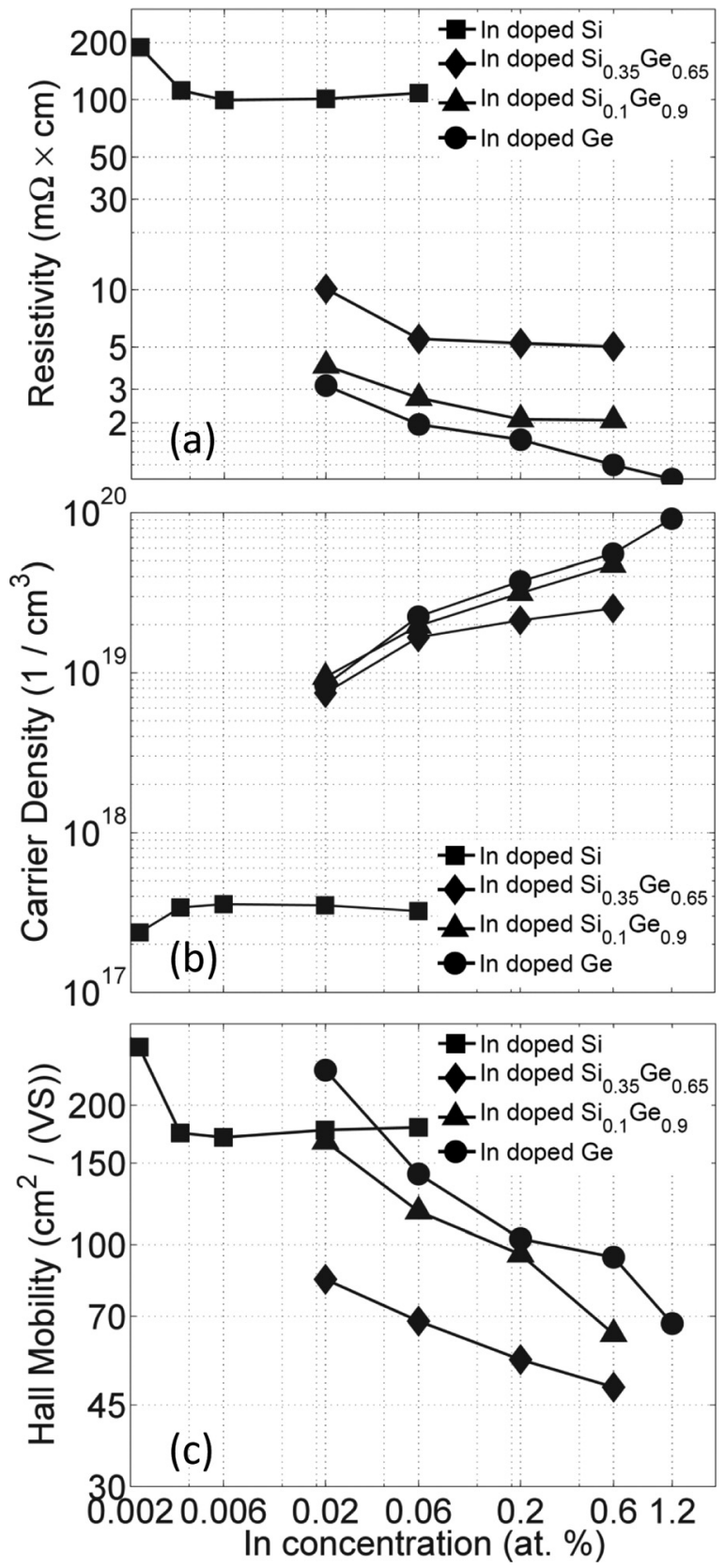

FIG. 1. (a) Resistivity, (b) carrier density, and (c) carrier mobility as a function of In concentration. Squares, diamonds, triangles, and circles represent In doped $\mathrm{Si}$, In doped $\mathrm{Si}_{0.35} \mathrm{Ge}_{0.65}$, In doped $\mathrm{Si}_{0.1} \mathrm{Ge}_{0.9}$, and In doped $\mathrm{Ge}$ (Ref. 9), respectively. Reproduced with permission from Feng et al., J. Appl. Phys. 118, 165701 (2015). Copyright 2015 AIP Publishing LLC. previous report. ${ }^{9}$ The In concentrations $(0.02-1.2$ at. \%) were determined with Rutherford Backscattering Spectrometry after annealing. A three-step annealing process in $\mathrm{N}_{2}$, at three different temperatures $\left(1000,800\right.$, and $600^{\circ} \mathrm{C}$ for $\mathrm{Si}, 700,550$, and $400{ }^{\circ} \mathrm{C}$ for $\mathrm{Si}_{1-\mathrm{x}} \mathrm{Ge}_{\mathrm{x}}$, and 550,450 , and $350^{\circ} \mathrm{C}$ for $\mathrm{Ge}$ ) for $0.5,1$, and $2 \mathrm{~h}$, respectively, was used to initially activate the implanted In atoms and reduce lattice disorder at the high temperatures, and then enhance the concentration of In-defect configurations by lowering the solid-solubility limit at the low temperatures.

Electrical characterization was performed using a LakeShore 7700A Series Hall effect electron transport measurement system at room temperature. Samples were patterned into clover-leaf van der Pauw geometries of $1 \mathrm{~cm}$ diameter for high measurement accuracy by means of photolithography and $\mathrm{KOH}$ or $\mathrm{H}_{2} \mathrm{O}_{2}$ etching at room temperature. ${ }^{16}$ To achieve an Ohmic contact, four $0.75 \mathrm{~mm}$ diameter, $200 \mathrm{~nm}$ thick Al contacts were thermally evaporated on the corners of the sample surface with photoresist as the mask. The Ohmic nature of the contacts was confirmed with current-voltage measurements.

For the synchrotron-based XAS measurements, we used a unique lift-off technique to isolate the In-rich thin films as described in Ref. 17. Fluorescence-mode x-ray absorption near edge structure (XANES) and extended $x$-ray absorption fine structure (EXAFS) measurements were performed at the XAS beamline of the Australian Synchrotron. In K-edge spectra were recorded with a $10 \times 10$ pixel-array Ge detector with samples measured at a temperature of $18 \mathrm{~K}$ to minimize thermal disorder. Multiple scans (3-6) were collected for each sample and averaged to maximize the signal-to-noise ratio. Data were recorded to a photoelectron wavenumber $(k)$ value of $12 \AA^{-1}$. For energy calibration, an In reference foil was simultaneously measured in transmission mode. Background subtraction, spectra alignment, and normalization of the EXAFS data were performed with ATHENA. ${ }^{18}$ Structural parameters were determined with ARTEMIS ${ }^{18}$ utilizing the IFFEFIT package ${ }^{19}$ with theoretical scattering amplitudes and phase shifts calculated ab-initio with FEFF8.4. ${ }^{20}$ The experimental data were simultaneously fit using $k$-weights of 2, 3, and 4. Linear combination fits of the XANES spectra were performed using the data of the lowest concentration samples (where EXAFS showed the In atoms were substitutional) and those of metallic In as standards.

Cross-sectional TEM measurements were performed with a Phillips CM300 operating at $300 \mathrm{kV}$. Samples were prepared with conventional methods: mechanical grinding to $80 \mu \mathrm{m}$, dimple grinding to $10-20 \mu \mathrm{m}$, and then final polishing

TABLE I. The In atoms active fraction as a function of In concentration in different substrates.

\begin{tabular}{lccccc}
\hline \hline In active fraction & 0.02 at. $\%$ & 0.06 at. $\%$ & 0.2 at. \% & 0.6 at. \% & 1.2 at. \% \\
\hline In doped $\mathrm{Si}$ & $1.9 \%$ & $0.65 \%$ & & & \\
In doped $\mathrm{Si}_{0.35} \mathrm{Ge}_{0.65}$ & $80.7 \%$ & $60.1 \%$ & $23.1 \%$ & $9.1 \%$ & \\
In doped $\mathrm{Si}_{0.1} \mathrm{Ge}_{0.9}$ & $100 \%$ & $73.1 \%$ & $35.1 \%$ & $17.6 \%$ & \\
In doped $\mathrm{Ge}^{\mathrm{a}}$ & $94.8 \%$ & $84.9 \%$ & $42.3 \%$ & $21.0 \%$ & $17.3 \%$ \\
\hline \hline
\end{tabular}

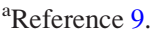


using Ar ion milling with the sample maintained at liquid $\mathrm{N}_{2}$ temperature.

To provide structurally-relaxed input models to the EXAFS simulations and calculate the binding energies of the In-In clusters, DFT calculations for substitutional In atom(s) in a $\mathrm{Si}_{1-\mathrm{x}} \mathrm{Ge}_{\mathrm{x}}$ lattice were performed with VASP. ${ }^{21}$ The generalized-gradient approximation (GGA) with the PerdewBurke-Ernzerhof (PBE) exchange-correlation function ${ }^{22}$ was utilized to calculate the interaction between the In atom(s) and the $2 \times 2 \times 2$ supercell, with a $10 \times 10 \times 10 \mathrm{k}$-point mesh using the Monkhorst-Pack sampling scheme. ${ }^{23}$ The projector augmented wave (PAW) pseudopotentials ${ }^{24}$ implemented in VASP were also used with a plane-wave cutoff energy of $240 \mathrm{eV}$. A conjugate-gradient (CG) geometry optimization algorithm was used to relax the lattice following a progressive relaxation procedure. ${ }^{9,25}$ Given $\mathrm{Si}_{1-\mathrm{x}} \mathrm{Ge}_{\mathrm{x}}$ is a random binary alloy, 15 models were generated for each stoichiometry with the appropriate number of Ge atoms randomly substituting Si atoms in a Si lattice. Calculations were performed individually for all 15 models, and the results were averaged. Such an approach for modeling random $\mathrm{Si}_{1-\mathrm{x}} \mathrm{Ge}_{\mathrm{x}}$ alloys has been previously justified. ${ }^{26-28}$ The validity of the models was further confirmed, as the Si-Ge bond lengths and the topological rigidity parameter (without In atoms present) agreed well with those in the published literature. $^{29,30}$

\section{RESULTS}

Figure 1 shows results of the three measured electrical parameters: resistivity, carrier density, and mobility, as a function of In concentration and $\mathrm{Si}_{1-\mathrm{x}} \mathrm{Ge}_{\mathrm{x}}$ stoichiometry. All
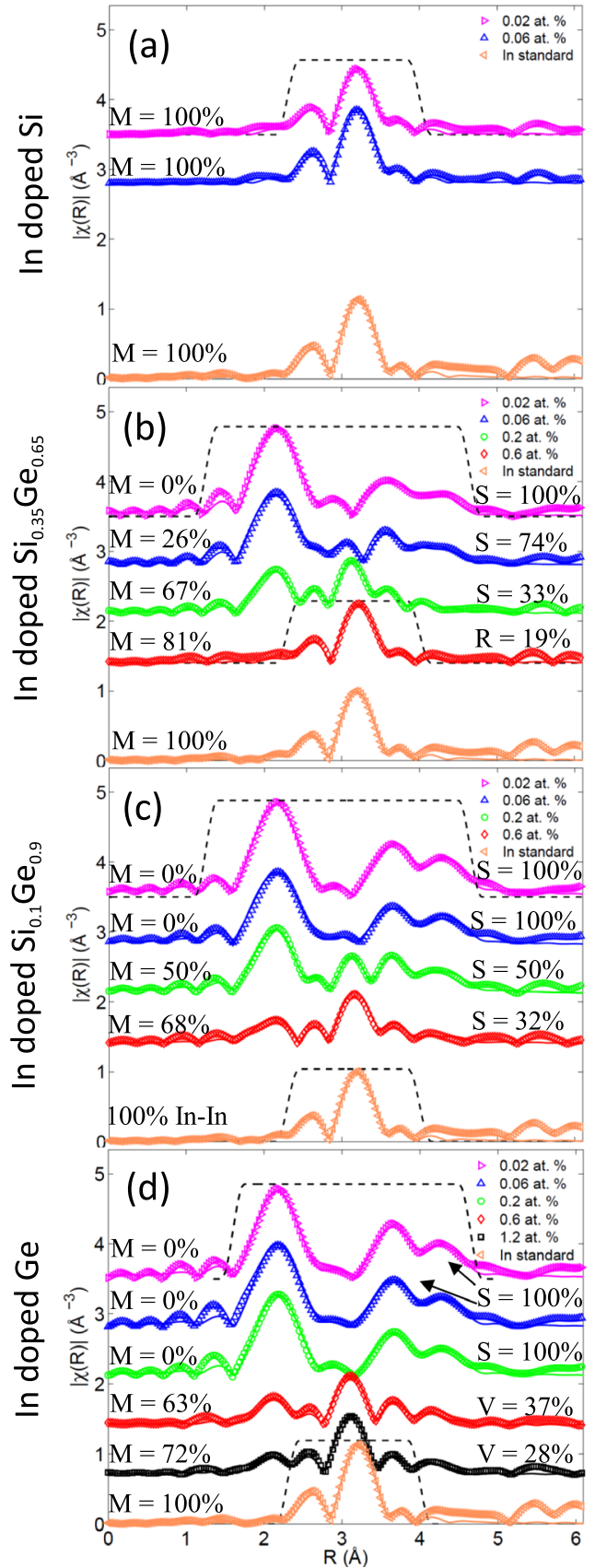

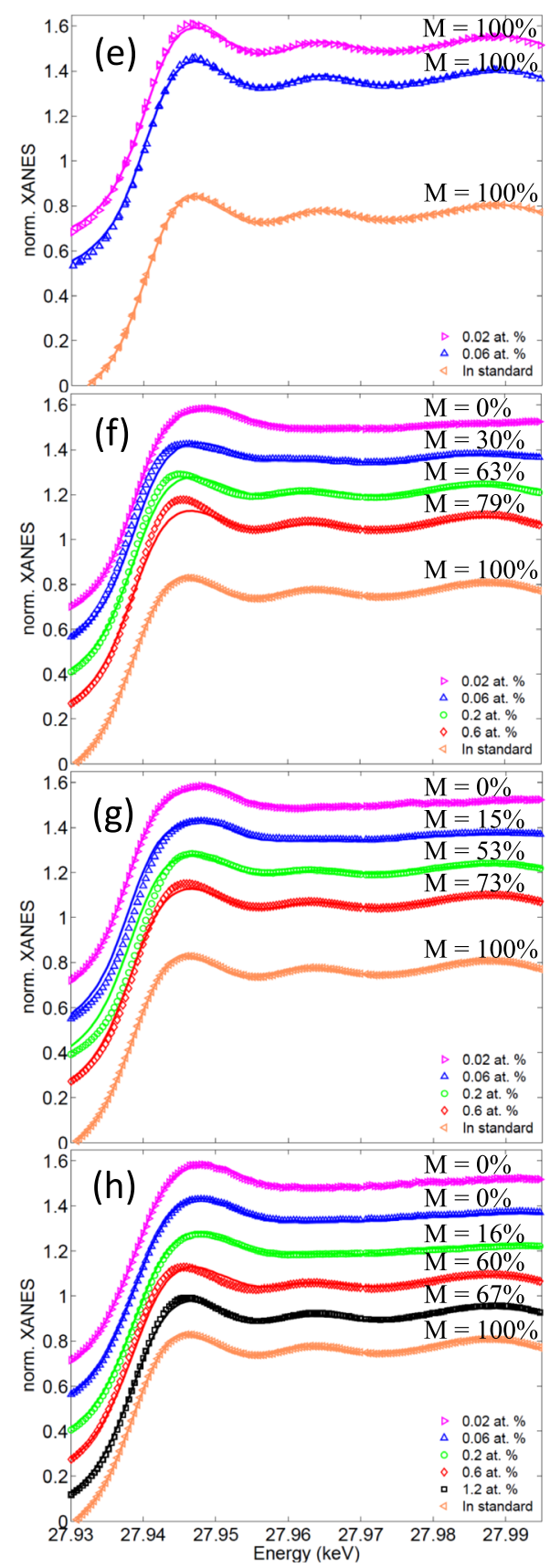

FIG. 2. (a)-(d) are the FT EXAFS spectra as a function of radial distance for the In implanted $\mathrm{Si}, \mathrm{Si}_{0.35} \mathrm{Ge}_{0.65}$, $\mathrm{Si}_{0.1} \mathrm{Ge}_{0.9}$, and $\mathrm{Ge}$ (Ref. 9) samples, respectively. Dashed lines show the Rrange windows used for the data fitting. (e)-(h) are the XANES spectra as a function of the incident photon energy for the In implanted $\mathrm{Si}, \mathrm{Si}_{0.35} \mathrm{Ge}_{0.65}$, $\mathrm{Si}_{0.1} \mathrm{Ge}_{0.9}$, and $\mathrm{Ge}$ (Ref. 9) samples, respectively. Spectra are offset vertically according to In concentration for clarity. Symbols represent the data while solid lines are best fits. Reproduced with permission from Feng et al., J. Appl. Phys. 118, 165701 (2015). Copyright 2015 AIP Publishing LLC. 
samples exhibited $p$-type conductivity. We first consider the In concentration dependence. In general, as the In concentration increased, the resistivity, carrier density, and mobility decreased, increased, and decreased, respectively, for each $\mathrm{Si}_{1-\mathrm{x}} \mathrm{Ge}_{\mathrm{x}}$ substrate (as anticipated). The exception is $\mathrm{Si}$ which we discuss later. The increased carrier density was simply the result of the increased In dopant concentration while the decreased mobility was due to the increased ionized impurity scattering. The trend in resistivity is determined by that of the carrier density and mobility, where the first is inversely proportional to the product of the second and third. For the In-doped Si samples, the three electrical parameters saturated beyond an In concentration of $\sim 0.004$ at. $\%$, indicating that the solid-solubility limit had exceeded (as confirmed later). For our annealing conditions, we thus estimate a solid-solubility limit for In in Si between 0.002 and 0.006 at. \%, a result in excellent agreement with that of Solmi et al. ${ }^{5}(0.0036$ at. \%). The electrically active fraction of implanted In atoms is shown in Table I, again as a function of In concentration and $\mathrm{Si}_{1-\mathrm{x}} \mathrm{Ge}_{\mathrm{x}}$ stoichiometry. Clearly, the electrically active fraction decreased as the In concentration increased. In addition to In atom precipitation, we will identify and discuss additional reasons for this deactivation of In atoms later.

We now consider the $\mathrm{Si}_{1-\mathrm{x}} \mathrm{Ge}_{\mathrm{x}}$ stoichiometry dependence. As the Ge fraction in the $\mathrm{Si}_{1-\mathrm{x}} \mathrm{Ge}_{\mathrm{x}}$ alloy increased, the resistivity, carrier density, and mobility decreased, increased, and increased, respectively. The increased carrier density was the result of an increased In solid-solubility as the Ge fraction increased, as we quantify later, while the increased mobility was the result of the increased carrier mobility in Ge relative to $\mathrm{Si}_{1-\mathrm{x}} \mathrm{Ge}_{\mathrm{x}}$ relative to $\mathrm{Si}$. The latter is consistent with an earlier study of $\mathrm{Si}_{1-\mathrm{x}} \mathrm{Ge}_{\mathrm{x}} \cdot{ }^{31}$ We note that the high mobility we measured for In-doped Si was in part due to the very low carrier density, and hence low level of ionized impurity scattering in this sample. The Hall mobility as a function of carrier concentration is in agreement with earlier studies. ${ }^{32,33}$ From Table I, the electrically active fraction of implanted In atoms increased as the Ge fraction in the $\mathrm{Si}_{1-\mathrm{x}} \mathrm{Ge}_{\mathrm{x}}$ alloy increased due to the corresponding increase of the In solid-solubility. Figure 1 readily demonstrated that, relative to $\mathrm{Si}$, low resistivity values have been achieved with In dopants in $\mathrm{Si}_{1-\mathrm{x}} \mathrm{Ge}_{\mathrm{x}}$ alloys.

To better understand the mechanism(s) by which In atoms were electrically activated/deactivated in $\mathrm{Si}_{1-\mathrm{x}} \mathrm{Ge}_{\mathrm{x}}$ alloys, we probed the atomic-scale environment around the In atoms with EXAFS (Figures 2(a)-2(d)) and XANES (Figures 2(e)-2(h)), supplementing these results with a

TABLE II. The estimated In solid solubility in $\mathrm{Si}_{1-x} \mathrm{Ge}_{\mathrm{x}}$ as a function of the $\mathrm{Si}_{1-\mathrm{x}} \mathrm{Ge}_{\mathrm{x}}$ stoichiometry.

\begin{tabular}{lc}
\hline \hline Substrates & In solid solubility (at. \%) \\
\hline $\mathrm{Si}$ & $0.002-0.006$ \\
$\mathrm{Si}_{0.35} \mathrm{Ge}_{0.65}$ & $0.02-0.06$ \\
$\mathrm{Si}_{0.1} \mathrm{Ge}_{0.9}$ & $0.06-0.2$ \\
$\mathrm{Ge}^{\mathrm{a}}$ & $0.2-0.6$ \\
\hline \hline
\end{tabular}

${ }^{\mathrm{a}}$ Reference 9 . structural disorder analysis performed with TEM (Figure 4). For the EXAFS analysis, all input models for the fittings were structurally relaxed by DFT. The bondlengths derived from the EXAFS fittings agreed well with those calculated by DFT. As earlier, we begin with the In concentration dependence. The Fourier-transformed EXAFS spectra generally comprised several components, typically In in a substitutional lattice position (with a peak at a non-phasecorrected radial distance of $\sim 2.3 \AA$ ) and In in a metallic In precipitate (with a peak at a non-phase-corrected radial distance of $\sim 3.2 \AA$ ). The relative fraction of these two components was clearly In concentration dependent, and the substitutional (S) and metallic (M) fractions decreased and increased, respectively, as the In concentration increased. The substitutional fractions (listed on the figure) determined by EXAFS were well correlated with the electrically active fractions determined by Hall Effect measurements (Table I) and thus the substitutional In atoms were indeed responsible for the production of charge carriers, not structural disorder as suggested by others. ${ }^{34}$ Note that to achieve improved EXAFS fittings, it was at times necessary to introduce a third component, either In in a random location $(\mathrm{R})$, with no contribution to the EXAFS spectra, ${ }^{35}$ or an In-vacancy pair, as described in detail in a previous report. ${ }^{9}$ XANES analysis complemented the EXAFS results. Linear combination fitting of the XANES spectra (Figures 2(e)-2(h)) with substitutional and metallic spectra (listed on the figure) yielded metallic fractions in excellent agreement with those determined by EXAFS.

We now consider the $\mathrm{Si}_{1-\mathrm{x}} \mathrm{Ge}_{\mathrm{x}}$ stoichiometry dependence. The appearance of the metallic In component in the EXAFS spectra enabled us to make quantitative estimates of the In solid-solubility limit in the $\mathrm{Si}_{1-\mathrm{x}} \mathrm{Ge}_{\mathrm{x}}$ alloys. Results are listed in Table II. Clearly the In solid-solubility limit increased as the Ge fraction in the $\mathrm{Si}_{1-\mathrm{x}} \mathrm{Ge}_{\mathrm{x}}$ alloy increased. This result was well explained by our DFT calculations, as described later.

The EXAFS results are summarized in Figure 3 as a function of both In concentration and $\mathrm{Si}_{1-\mathrm{x}} \mathrm{Ge}_{\mathrm{x}}$ alloy stoichiometry. As earlier, this figure demonstrates that the metallic

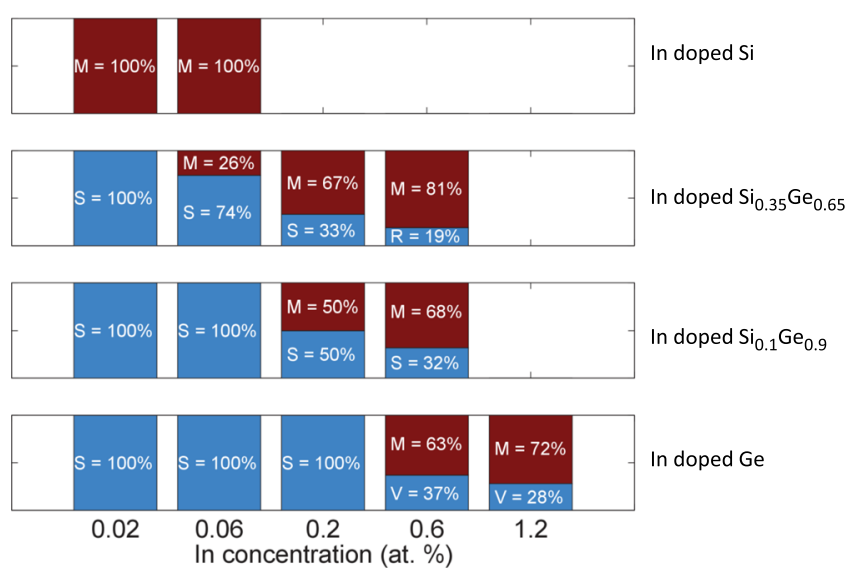

FIG. 3. A bar chart summarizing the fractions of the implanted In atoms in substitutional sites of $\mathrm{Si}_{1-\mathrm{x}} \mathrm{Ge}_{\mathrm{x}}(\mathrm{S})$, in a metallic In environment (M), in a random lattice location $(\mathrm{R})$, and in substitutional sites pairing with vacancy (V). The lattice locations were determined by EXAFS as in Figure 2. 


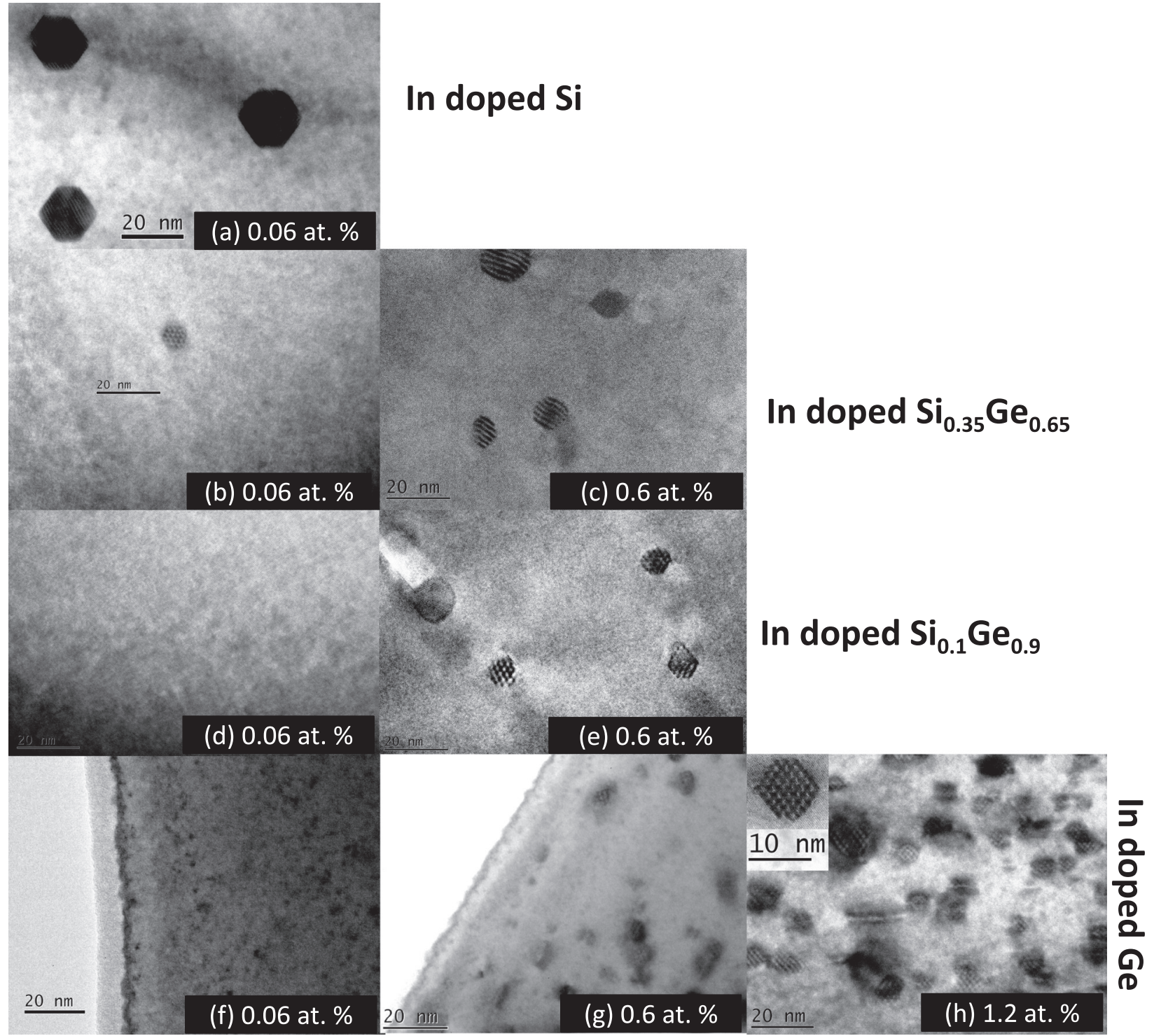

FIG. 4. Cross section TEM images for the samples of different implantation concentration (horizontal) and substrates stoichiometry (vertical). The inset in (h) shows a high resolution image of a metallic In precipitate (Ref. 9). Reproduced with permission from Feng et al., J. Appl. Phys. 118, 165701 (2015). Copyright 2015 AIP Publishing LLC.

fraction increased as the In concentration increased. Furthermore, the solid-solubility of In in the $\mathrm{Si}_{1-\mathrm{x}} \mathrm{Ge}_{\mathrm{x}}$ alloy increased as the Ge fraction increased (and hence the onset of precipitation was observed at higher In concentrations as the Ge fraction increased). The figure shows that substitutional In atoms were electrically active at low In concentrations, and In metal precipitation was the process by which In atoms become electrically inactive at high In concentrations.

TEM analysis was entirely consistent with EXAFS and XANES results. Figure 4 shows cross-sectional images for several In concentrations as a function of $\mathrm{Si}_{1-\mathrm{x}} \mathrm{Ge}_{\mathrm{x}}$ alloy stoichiometry. The limited field of view inhibited quantification but clearly the number of In precipitates increased as the In concentration increased.

The experimental results presented earlier demonstrated a clear dependence on $\mathrm{Si}_{1-\mathrm{x}} \mathrm{Ge}_{\mathrm{x}}$ alloy stoichiometry. To identify and understand the reasons for this behavior, we used DFT calculations for two substitutional In atoms in a 64-atom $2 \times 2 \times 2 \quad \mathrm{Si}_{1-\mathrm{x}} \mathrm{Ge}_{\mathrm{x}}$ super-cell over the entire stoichiometry range from $x=0$ to 1 . Calculations were performed for four In cluster configurations, with the second In atom positioned as either the first, second, or third nearest neighbor (NN) of the central In atom in addition to an In atom at the super-cell vertex, the maximum possible separation. Figure 5 shows binding energies of In clusters as a function of $\mathrm{Si}_{1-\mathrm{x}} \mathrm{Ge}_{\mathrm{x}}$ alloy stoichiometry and the separation between the two In atoms. In general, the binding energies trended downward (more favorable) as the Ge fraction decreased. The binding energies also trended downward as the separation between the two In atoms decreased. Equivalently, the In atoms preferred to pair. The difference in binding energies as a function of the separation became more pronounced as the Ge fraction decreased. Equivalently, there was a greater driving force for In atoms to pair as the $\mathrm{Ge}$ fraction decreased. For In clusters in $\mathrm{Si}$, the calculated binding energies were $-0.62(1 \mathrm{st} \mathrm{NN}),-0.40$ (2nd NN), -0.31 ( $3 \mathrm{rd} \mathrm{NN}$ ), and -0.26 (diagonal) $\mathrm{eV}$ for the four configurations, agreeing well with the results previously 


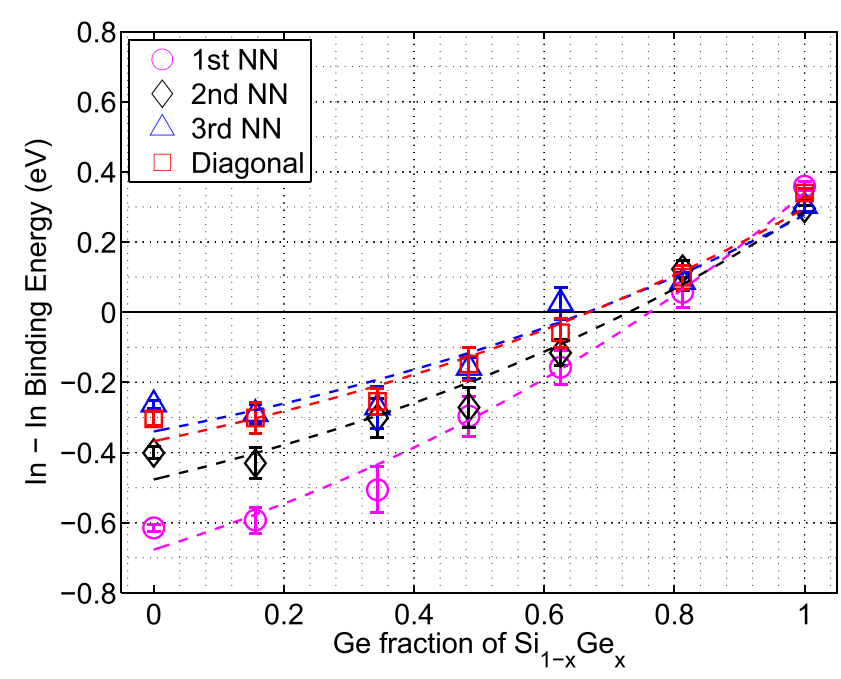

FIG. 5. The binding energies of two In atoms in substitutional sites of $\mathrm{Si}_{1-\mathrm{x}} \mathrm{Ge}_{\mathrm{x}}$ as a function of $\mathrm{Ge}$ composition. Circle, diamond, and triangle represent the binding energies for the two In atoms as first, second, and third nearest neighbor $(\mathrm{NN})$, respectively; square represents those of two In atoms in diagonal locations (one In atom in the center and the other in the vertex of the supercell, the farthest distance the two atoms can be positioned). Dashed lines are the best fits of the data with an exponential function.

reported by Yamauchi and Aoki. ${ }^{1}$ The negative binding energies indicated that In atoms tend to aggregate spontaneously ${ }^{1}$ for $x \lessgtr 0.7$. This approximate stoichiometry marked the transition from energetically favorable $(x \lesssim 0.7)$ to energetically unfavorable $(x \geq 0.7)$ for In-In pair formation. This theoretical result has identified the reason for the increased In solidsolubility limit as the Ge fraction in $\mathrm{Si}_{1-\mathrm{x}} \mathrm{Ge}_{\mathrm{x}}$ increased.

\section{CONCLUSION}

We have characterized the electrical and structural properties of In-implanted $\mathrm{Si}_{1-\mathrm{x}} \mathrm{Ge}_{\mathrm{x}}$. Both the In concentration and $\mathrm{Si}_{1-\mathrm{x}} \mathrm{Ge}_{\mathrm{x}}$ alloy stoichiometry dependencies have been examined. The In solid-solubility limit has been quantified, and it increases as the Ge fraction in the $\mathrm{Si}_{1-\mathrm{x}} \mathrm{Ge}_{\mathrm{x}}$ alloy increases. In metal precipitation (at In concentrations in excess of the solid-solubility limit) was the primary reason for the electrical deactivation of In atoms. A complementary theoretical study of In-In pairing in $\mathrm{Si}_{1-\mathrm{x}} \mathrm{Ge}_{\mathrm{x}}$ alloys demonstrated that pairing was energetically favorable for $\mathrm{x} \lessgtr 0.7$ and identified the reason for the trend in In solid-solubility limit as a function of $\mathrm{Si}_{1-\mathrm{x}} \mathrm{Ge}_{\mathrm{x}}$ alloy stoichiometry. Our results have clearly demonstrated that In implantation in $\mathrm{Si}_{1-\mathrm{x}} \mathrm{Ge}_{\mathrm{x}}$ alloys is an effective means of achieving the low resistivity values necessary for advanced electronic devices.

\section{ACKNOWLEDGMENTS}

We acknowledge access to NCRIS and AMMRF infrastructure at the Australian National University including the Australian National Fabrication Facility, the Heavy Ion Accelerator Capability, and the Center for Advanced
Microscopy. We also thank the Australian Research Council and Australian Synchrotron for support.

${ }^{1}$ J. Yamauchi and N. Aoki, Phys. Rev. B 71, 205205 (2005).

${ }^{2}$ S. Decoster, B. De Vries, U. Wahl, J. G. Correia, and A. Vantomme, J. Appl. Phys. 105, 083522 (2009).

${ }^{3}$ H. Boudinov, J. P. de Souza, and C. K. Saul, J. Appl. Phys. 86, 5909 (1999).

${ }^{4}$ F. d'Acapito, Y. Shimizu, S. Scalese, M. Italia, P. Alippi, and S. Grasso, Appl. Phys. Lett. 88, 212102 (2006).

${ }^{5}$ S. Solmi, A. Parisini, M. Bersani, D. Giubertoni, V. Soncini, G. Carnevale, A. Benvenuti, and A. Marmiroli, J. Appl. Phys. 92, 1361 (2002).

${ }^{6}$ A. Onton, P. Fisher, and A. K. Ramdas, Phys. Rev. 163, 686 (1967).

${ }^{7}$ R. Kube, H. Bracht, A. Chroneos, M. Posselt, and B. Schmidt, J. Appl. Phys. 106, 063534 (2009).

${ }^{8}$ R. Hull and J. C. Bean, Germanium Silicon: Physics and Materials, Semiconductors and Semimetals (Academic, San Diego, 1999).

${ }^{9}$ R. Feng, F. Kremer, D. J. Sprouster, S. Mirzaei, S. Decoster, C. J. Glover, S. A. Medling, S. P. Russo, and M. C. Ridgway, J. Appl. Phys. 118, 165701 (2015).

${ }^{10}$ T. H. Geballe and F. J. Morin, Phys. Rev. 95, 1085 (1954).

${ }^{11}$ K. J. Kuhn, A. Murthy, R. Kotlyar, and M. Kuhn, ECS Trans. 33, 3 (2010).

${ }^{12}$ I. Berbezier and A. Ronda, Surf. Sci. Rep. 64, 47 (2009).

${ }^{13}$ A. Chroneos, H. Bracht, R. W. Grimes, and B. P. Uberuaga, Appl. Phys. Lett. 92, 172103 (2008).

${ }^{14}$ A. Chroneos, R. Kube, H. Bracht, R. W. Grimes, and U. Schwingenschlögl, Chem. Phys. Lett. 490, 38 (2010).

${ }^{15}$ J. F. Ziegler and J. M. Manoyan, Nucl. Instrum. Methods Phys. Res., Sec. B 35, 215 (1988).

${ }^{16}$ G. De Mey, Arch. Electron. Uebertragungstech. 27, 309 (1973).

${ }^{17}$ S. Decoster, C. J. Glover, B. Johannessen, R. Giulian, D. J. Sprouster, P. Kluth, L. L. Araujo, Z. S. Hussain, C. Schnohr, H. Salama, F. Kremer, K. Temst, A. Vantomme, and M. C. Ridgway, J. Synchrotron. Radiat. 20, 426 (2013).

${ }^{18}$ B. Ravel and M. Newville, J. Synchrotron Radiat. 12, 537 (2005).

${ }^{19}$ M. Newville, J. Synchrotron. Radiat. 8, 322 (2001).

${ }^{20}$ A. L. Ankudinov, B. Ravel, J. J. Rehr, and S. D. Conradson, Phys. Rev. B $\mathbf{5 8 ,} 7565$ (1998).

${ }^{21}$ G. Kresse and J. Furthmüller, Phys. Rev. B 54, 11169 (1996).

${ }^{22}$ J. P. Perdew, K. Burke, and M. Ernzerhof, Phys. Rev. Lett. 77, 3865 (1996).

${ }^{23}$ J. D. Pack and H. J. Monkhorst, Phys. Rev. B 16, 1748 (1977).

${ }^{24}$ G. Kresse and D. Joubert, Phys. Rev. B 59, 1758 (1999).

${ }^{25}$ S. P. Russo, I. E. Grey, and N. C. Wilson, J. Phys. Chem. C 112, 7653 (2008).

${ }^{26}$ A. Carvalho, J. Coutinho, R. Jones, J. Goss, M. Barroso, and P. R. Briddon, Phys. Rev. B 78, 125208 (2008).

${ }^{27}$ V. J. B. Torres, J. Coutinha, P. R. Briddon, and M. Barroso, J. Non-Cryst. Solids 352, 1279 (2006).

${ }^{28}$ A. Balsas, J. Coutinho, V. J. B. Torres, P. R. Briddon, and M. Barroso, Phys. Rev. B 70, 085201 (2004).

${ }^{29}$ M. C. Ridgway, K. M. Yu, C. J. Glover, G. J. Foran, C. Clerc, J. L. Hansen, and A. N. Larsen, Phys. Rev. B 60, 10831 (1999).

${ }^{30}$ J. C. Aubry, T. Tyliszczak, A. P. Hitchcock, J.-M. Baribeau, and T. E. Jackman, Phys. Rev. B 59, 12872 (1999).

${ }^{31}$ M. V. Fischetti and S. E. Laux, J. Appl. Phys. 80, 2234 (1996).

${ }^{32}$ C. Jacoboni, C. Canali, G. Ottaviani, and A. A. Quaranta, Solid State Electron. 20, 77 (1977).

${ }^{33}$ J. M. Dorkel and Ph. Leturcq, Solid State Electron. 24, 821 (1981).

${ }^{34}$ L. Romano, G. Impellizzeri, and M. G. Grimaldi, Mater. Sci. Semicond. Process. 15, 703 (2012).

${ }^{35}$ S. Decoster, B. Johannessen, C. J. Glover, S. Cottenier, T. Bierschenk, H. Salama, F. Kremer, K. Temst, A. Vantomme, and M. C. Ridgway, Appl. Phys. Lett. 101, 261904 (2012). 